\title{
COMMISSION 8. (MERIDIAN ASTRONOMY.)
}

President: Dr J. Jackson.

SECRETARY: Dr C. H. HINS.

Dr Boss stated that he hoped to publish the first two volumes of the General Catalogue by the middle of the next year and the complete catalogue of four volumes by the end of 1936 . A 5 th volume containing the introduction will be published later.

Dr Jackson reported that Prof. Kopff would postpone the choice of the 3000 fundamental stars for photography till after the publication of Boss's G.C.

Dr Gerasimoviç reported that the fundamental stars of magnitudes $7^{\mathrm{m} \cdot} \cdot 5^{-8^{\mathrm{m}} \cdot 5}$ which have been selected by Dneprovski for observation at Pulkovo and Nikolayev were stars of the $M$ giant type.

Dr Gerasimoviç, Prof. Schlesinger and Dr Brouwer took part in a short discussion on the problem of the determination of the errors of our fundamental systems by means of the observation of minor planets. The chairman in conclusion referred to the excellent work done on this problem by Voronoff.

Dr Hins reported the results of the expedition to Kenya Colony, i.e. the corrections to the declinations of the P.G.C. between $-50^{\circ}$ to $+50^{\circ}$ declination derived from the observations made with an azimuth instrument near the earth's equator. The results are claimed to be free of the vertical component of atmospheric refraction and independent of the latitude of the observer.

It seems that the corrections found depend on whether the positions of the P.G.C. are based on observations made either at northern or southern observatories or at both.

Dr A. Lambert asked for the collaboration especially of southern observatories for the observation of galactic stars.

The following resolution was approved for submission to the General Assembly:

"La Commission attire l'attention des observatoires sur la proposition relative à l'observation des étoiles galactiques en vue de l'étude des mouvements propres des étoiles lointaines, de cette zone.

"Elle recommande aux observatoires, et particulièrement à ceux de l'hémisphère sud, qui en ont la possibilité, d'entreprendre ce travail et de se mettre en rapport pour ce sujet avec l'Observatoire de Paris."

Mme Chandon emphasized the importance of observations with instruments of broken type in regard to removing personal and instrumental errors and the importance of observing by the method of equa saltitudes for comparing stars of widely different right ascensions.

Dr Baldet presented the first proof of a Fundamental Catalogue of Star Places numbering 872 stars with an average of 27 observations per star, observed by him at Alger in the years $1912-1922$.

The observations were of a fully fundamental nature. As a result of the death of Prof. Gonnessiat it was difficult to give an introduction as detailed as is desirable.

Dr Danjon referred to the meridian instrument which he had constructed and used at Strasbourg. The instrument could be seen at the exhibition.

Dr W. D. Lambert of the U.S. Coast and Goedetic Survey presented a paper, "Geodetic Astronomy in the United States."

It was agreed at the suggestion of Prof. Schlesinger to reappoint the Sub-commission on the determination of star places by photography.

For the report of a joint meeting with Commissions 4 and 20 see p. 282. 